\title{
Thinking on the Essence of College Creative Education and Creative Talent Cultivation
}

\author{
Wang Ke \\ School of Economy and Management \\ Shenyang Aerospace University \\ Shenyang City, China
}

\begin{abstract}
With the constant reform on the education cause in our country, we are getting increasingly deeper understanding of creative education and identifying that, to realize the growth of the national economy in current global era, attention must be paid to creative education and creation talent cultivation. The competition in the 21 st century is fundamentally the competition in talents, especially creative talents are holding a special significance for a country. College creative education is utterly important for cultivating creative talents. In the thesis, the essence of college creative education is introduced and such is pointed out as the importance of creative education for creative talent cultivation and the necessity of proposing some proper reform measures to realize talents strategy for powerful nation.
\end{abstract}

Keywords-College education reform; The essence of creative education; Talent cultivation; Thinking exploration

Creation is the power for development and the essential demand for science and technology. Only creation makes us moving. In face of the rapid development of science and technology today, it is largely relied on the creative talents to achieve competitive advantages in the world, and a group of pioneering and creative talents can directly influence a country's comprehensive power. Education holds a key role in talent cultivation. Judged from the current situation, creative education is the inevitable development trend, and a good creative education decides creative talent cultivation and the improvement of a country's comprehensive power. Therefore, colleges are shouldering a holly and fundamental mission in today's world.

\section{ANALYSIS ON THE ESSENCE OF COLLEGE CREATIVE}

\section{EDUCATION}

Creative education is a higher-level education form. In the current wave of educational reform, it is mainly focusing on the reform of creative education, which mainly aims to develop the college students' creative spirit and ability to meet the demands of the rapid progress of science and technology and allow them to make constant contributions to the society.

\section{A. The essence of creative spirit and ability}

Creative spirit is a scientific spirit with the courage to doubt the traditional concept or theory and raise new ideas. It is externally reflected by inventive design and pioneering spirit, and the psychological inclination of pursuing creative consciousness and positively exploring new things. Creative education mainly aims to stimulate the students' subjective consciousness and sense of curiosity, and guide them to explore in the unknown fields. Therefore, it is imperative to develop their thinking capacity, infuse question awareness, encourage them to give their own ideas, flexibly put knowledge into practice and question solution.

Creative ability refers to the comprehensive change of the thinking ability and knowledge skills in the process of activities and question research. It is not only influenced by mental factors and also by non-mental factors, such as confidence and strategy. It is a combination of abilities, much required by this society of science and technology. The significance of creative education for this ability can be reflected in many ways, either in knowledge system or in practice ability.

\section{B. The relation between creative spirit and ability}

The combination of creative spirit and ability can turn to creativity in a person. A man who has the capacity of creativity can be sort of creative talent. Creative spirit is the soul and power of creation and the internal requirement of creative ability. To realize creation, it requires creative spirit to emancipate the thought, and achieve constant development and progress. Creative ability is the external reflection of creativity. Those who have creative thought but lack creative ability cannot meet the development of the society likewise. Therefore, only the combination of the two can fully reflect the creativity.

\section{THE PROBLEMS IN CULTIVATING CREATIVE TALENTS}

\section{A. The inconformity of the traditional teaching mode to the requirement of creative education}

Influenced by the traditional educational concept, we generally focus on cultivating knowledge talented person. In the process of curriculum development, knowledge-centered theory has a strong influence, emphasizing the priority of the subject knowledge in curriculum development; however, such theory has a huge restraint on innovative education. That has produced a big gap between the actual teaching mode in our country and the required mode by the creative education, and thus badly affected the implementation of thee creative education and the creative talent cultivation. The emphasis on knowledge in curriculum arrangement has fragmented the complete set of knowledge structure and made the knowledge hard to use. The traditional teaching system has seriously hindered the implementation of creative 
education in our country, since it leaves the students in a passive position and minimizes their initiative; whereas the creative education mainly focuses on cultivating their subjective exploration ability. Therefore, the latter can inevitably weaken their creative spirit and goes against the further implementation of creative education.

\section{B. The ignorance for the importance of practice teaching in curriculum arrangement}

In curriculum arrangement, colleges pay much attention to improving the students' theory knowledge, but the efforts are less in developing their practice ability. Despite some experiment courses, it can be commonly seen the inadequate practice in experiment or the practice stuck in formalization, which are restricting the development of the creative education likewise. The practice teaching at current stage is mainly to verify the theoretic knowledge and one-sidedly intensify the idea of "all the teachers say is truth". The excessive emphasis on the teachers' authority tends to ignore the student's initiative. It shall be known that practice curriculum is utterly important for creative education, since the students' creative spirit and ability both derive from practice. Only by leaving the students in persistent operation and practice, making them discover and raise questions, can we be able to constantly exercise their thinking and creative ability. Simply infusing theoretic knowledge will sacrifice the time for using their hands and mind, restrict the development of their creative awareness and produce some knowledge talented persons that cannot meet the social demands.

\section{The defects in educational management mechanism}

In terms of our management mechanism, the traditional management mechanism lacks humanistic care and restricts the development of college creative education and the cultivation of creative talents. Analyzing from micro perspective, it is mainly reflected the management mechanism on students. The strict management mode has seriously restricted the students' initiative and left them a rebellious mentality against the management rule and school education. While in terms of student management, the mechanical principle of rules departs from humanistic care and forms a tight teacher-student relation. As the students' creative awareness was ruthlessly dampened in the long-term restraints, they only end up with a poor creative mind and ability. Judging from the macro perspective, that can be mainly seen from the rigid rule of the government body over the colleges, so that they have to follow the fixed rules and lose their initiative, decision-making qualification and even their own teaching characteristics, also bad for the cultivation of the creative talents. The talents cultivated from rigid teaching management mode tend to have rigid mind, compared with the demand for a flexible and leapfrog thinking mode of the creative talents. In addition, the restraint also comes from the tidy education mechanism, which also weakens the students' creative awareness. In the current era of knowledge-based economy, we shall pay more attention to the development of the creative education and emphasis on the importance of the creative talents.

\section{CREATIVE TALENT CUlTiVAtion STRATEGy BY}

\section{COLLEGE CREATIVE EDUCATION}

\section{A. Realize the change of educational thought and grasp the essence of the creative education}

In the 21 st century, as the talents are required to have a creative mind and ability, we are also expecting the colleges to change their education thought, grasp the essence of the creative education and work hard to deepen creative education reform. To shift the knowledge talented persons to the persons with creative mind, we shall not purely focus on imparting textbook knowledge in terms of talent cultivation, but also allow them to flexibly apply the knowledge and cultivate their creative mind through practice courses shift the educational emphasis onto the life-long learning program, create a creative academic atmosphere to improve their creative awareness and ability and stimulate their potential. There is a fundamental difference between creative and traditional education, which requires the colleges to make fundamental change in education reform and constantly pushing our creative education system reform, instead of sticking in a formalized style.

\section{B. Optimize curriculum system and teaching contents}

In terms of curriculum arrangement, attention shall be paid to the ratio of practice program, so as to discard the existing idea of overemphasizing theory and formalizing the practice courses. While establishing a proper curriculum structure system, we shall get aware that, besides the firm knowledge basis and proper knowledge structure, the creative talents shall also develop a positive creative mind and strong creative ability which are quite essential for them. At present, our colleges are still adopting a rigid curriculum and teaching mode, and as a result, they have produced a bunch of graduates with poor comprehensive ability and adaptability, hard to meet the social demands.

In the aspect of curriculum system and teaching content, we shall place emphasis onto the development of the students' comprehensive ability. Under the goal of complete basic knowledge, proficient professional skill and strong creative ability, we shall break through the traditional mode of program separation of liberal and science to enhance their comprehensive knowledge quality. At the same time, efforts shall be made to constantly upgrade the teaching contents, keep them up with the international step and more inclined to inspiring the students' explorative and creative mind, as an attempt to produce the talents meeting the cultivation goal of the creative education.

\section{Optimize teaching method and realize modern teaching}

It is very necessary to reform teaching method. A good teaching method can stimulate the students' learning interest and creative mind. In modern education, the traditional teaching method can no longer meet the actual demand. Modern teaching media can better help stimulate the students' creative mind, and essentially improve their sensual ability and knowledge acquisition capacity. 
However, it is inadvisable to purely rely on the multimedia teaching. The teachers are not only required impart knowledge, and also to make full use of the advantages of multimedia, pay attention to interactions with students, prevent the loss of confidence for lagging down the teachers' pace. Therefore, optimizing teaching method imposes a high requirement on teachers.

\section{Improve teaching evaluation system}

The current student evaluation system imposes too high demand on their grades, which makes it difficult for them to get rid of the shackle of the exam-oriented education. To get prepared for exams, they tend to learn by rote, which goes against the creative education. Therefore, it is key to improve the evaluation system, implement various exam forms, change the traditional exam mode, diversify the evaluation system with their creative works and other activity performance as the basis of reference, which can help stimulate the innovative enthusiasm and create a creative atmosphere across the college.

\section{CONCLUSION}

Creative education is an important direction for China's education reform, since it can better conform to the educational standard of creative talent cultivation. Therefore, the colleges shall identify the current tasks, learn the overseas advanced mode either in concepts, curriculum arrangement and teaching method, and find out the improper links in the educational mode. Despite the long performance of the traditional teaching mode, keeping up with the times is the fundament of development. It is the most important to constantly deepen teaching system reform and cultivate more comprehensive creative talents for our country, in order to keep a superior position in international competition. In the era of scientific and technological information, the importance of talents for a country is apparent, especially the importance of the creative talents as the main power for the national development. Therefore, creative talent cultivation is the current important task.

\section{REFERENCES}

[1] Fan Chunli, Thinking on the Essence of College Creative Education and the Cultivation of Creative Talents [J]. Jianghan University Journal (social science version) 2010,03:110-112

[2] Lu Man, New Thinking on College Creative Talent Cultivation [J] Heilongjiang College of Education Journal, 10/2010:110-112

[3] Jiang Wei, Zhang Qiuhui, Weng Jiamin, Strategic Analysis on College Creative Talent Cultivation under the Background of Quality Education [J], HR Management, 2014,02: 156-157

[4] Zhang Xiying, Thinking on College Teaching Material Construction and Creative Talent Cultivation [J], A Vast View on Publishing, 2014, 18:80-81

[5] Li Xue, Thinking on the $21^{\text {st }}$ Creative Talent Cultivation---Interview Record for China's Higher Education Management Research Association deputy manager, professor and doctoral advisor Tian Jianguo [J] Economist, 2011,18:80-81

[6] Cheng Peng, Peng Yan, Wang Huan, Consideration from the Comparison of Our National Creative Talent Cultivation Modes [J], Science and Technology Creation Guide, 2011,09:142-143

[7] Liu Wei, Thinking on College Creative entrepreneurial education Talent Cultivation System Building [J] Educational Science, 2011,05:64-67.

[8] Chang Xiujuan, Thinking on College Creative Talent [J] Heilongiiang Education (Higher Education Research and Evaluation) 03/2012:80-81

[9] Lv Lili, Thinking on Science Education in College Creative Talent Cultivation $[\mathrm{J}]$, Changzhou Information Vocational and Technical College Journal, 2012,02:11-13

[10] Li Tao, Discussion on Creative Practice Education and College Creative Talent Cultivation [J], Social Scientist, 2012,S1:175-176.

[11] Zhang Zhijun, Xu Wenhui, Li Sainan, Discussion on Educational Strategy in College Creative Talent Cultivation [J], Baicheng Normal College Journal 2012,05:93-96.

[12] Tie Raorao. Brief Discussion of Creative Talent Cultivation and College Humanistic Quality Education [J] Education of Art, 2014,11:50

[13] Wu Yadong, Discussion on College Quality Education and Creative Talent [J], West China Science, 2013,05:116-117

[14] Hu Jinzhi, The Deep Thinking on College Teacher Quality Education and Creative Talent Cultivation [J], College Education. 2013,16:16-17.

[15] Liu Liyuan, Thinking on College Creative Talent Cultivation [J], Science Vision, 2015,19:112-113. 